University of Nebraska - Lincoln

DigitalCommons@University of Nebraska - Lincoln

Faculty Publications from the Department of Engineering Mechanics

Mechanical \& Materials Engineering,

Department of

$3-2001$

\title{
Analysis of microdamage evolution histories in composites
}

Yuris A. Dzenis

University of Nebraska - Lincoln, ydzenis@unl.edu

Jie Qian

University of Nebraska-Lincoln

Follow this and additional works at: https://digitalcommons.unl.edu/engineeringmechanicsfacpub

Part of the Mechanical Engineering Commons

Dzenis, Yuris A. and Qian, Jie, "Analysis of microdamage evolution histories in composites" (2001). Faculty Publications from the Department of Engineering Mechanics. 63.

https://digitalcommons.unl.edu/engineeringmechanicsfacpub/63

This Article is brought to you for free and open access by the Mechanical \& Materials Engineering, Department of at DigitalCommons@University of Nebraska - Lincoln. It has been accepted for inclusion in Faculty Publications from the Department of Engineering Mechanics by an authorized administrator of DigitalCommons@University of Nebraska - Lincoln. 
Published in International Journal of Solids and Structures 38:10-13 (March 2001), pp. 1831-1854; doi: 10.1016/S0020-7683(00)00138-4 Copyright ( 2001 Published by Elsevier Science Ltd.

Used by permission. http://www.elsevier.com/locate/ijsolstr

Submitted December 13, 1999; revised February 25, 2000; published online January 10, 2001.

\title{
Analysis of microdamage evolution histories in composites
}

\author{
Yuris A. Dzenis and Jie Qian \\ Department of Engineering Mechanics, Center for Materials Research and Analysis, \\ University of Nebraska-Lincoln, Lincoln, NE 68588-0526, USA \\ Corresponding author - Y. A. Dzenis, tel 402 472-0713, fax 402 472-8292, email ydzenis@unl.edu
}

\begin{abstract}
Evolution of microdamage in advanced composites was experimentally studied in this paper. A new method of acoustic emission (AE) analysis of histories of different damage mechanisms was formulated based on a combination of transient $\mathrm{AE}$ classification and multiparameter filtering. The capabilities of the method were illustrated on examples of damage evolution in several graphite/epoxy composites. Three characteristic AE waveforms with different frequency spectra were identified based on the transient analysis. Regions occupied by these waveforms in the amplitude-rise time parametric space were identified for the $[0]_{8}$ and $[90]_{16}$ unidirectional composites. Multiparameter filtering was applied to extract evolution histories for the characteristic waveforms. The results were compared with actual damage in the specimens and the three characteristic AE waveforms were associated with matrix cracks, fiber breaks, and "macrodamage," such as delaminations or longitudinal splitting in unidirectional plies. The multiparameter filters based on the analysis of the unidirectional composites were used to extract the damage evolution histories for the cross-ply $[0 / 90]_{3 S}$ and angle-ply $[ \pm 45]_{4 S}$ composites. The results compared favorably with the observed damage in these materials. An inverse analysis of the quality of the multiparameter filtering for the laminated composites indicated that the filters developed for unidirectional composites can be applied to the analysis of laminated composites with reasonable reliability. The new method of acoustic emission analysis of damage micromechanisms is expected to be especially advantageous for fatigue damage evolution studies in composites and structures.
\end{abstract}

Keywords: composites, damage micromechanisms, damage evolution, acoustic emission analysis

\section{Introduction}

\subsection{Damage in composites}

Homogeneous engineering materials subjected to loads usually fail as a result of critical crack propagation. Advanced composite materials, in contrast, exhibit gradual damage accumulation to failure (Masters and Reifsnider, 1980). Damage development in composites starts early in the loading process 
due to the inherent inhomogeneity of these materials. Advanced composite materials consist of reinforcing elements, such as fibers, embedded in a matrix. The reinforcing elements are stiff and strong, and often exhibit substantial anisotropy of mechanical properties. The matrix material, on the other hand, is usually soft and isotropic. An external load applied to such a composite results in severely inhomogeneous stress and strain fields (Tsai and Hahn, 1980). Early damage starts to develop in the microvolumes within the composite in which the localized stress has reached the strength or fracture limit of a particular constituent or an interface between the constituents. The resulting crack sizes correlate with the sizes of material inhomogeneities responsible for the stress inhomogeneity. The microcracks that develop are usually too small to cause final failure of the composite. A substantial number of these microcracks accumulate in the composite before failure.

Were it not for the inherent randomness of composite microstructure and properties, the microcracks of a particular type would all occur in the repeating volumes of the material at the same load. However, the microstructure of composites is random at the microscale (Gunyaev, 1985). Parameters, such as volume fraction and orientation of fibers, ply thickness, and localized fiber spacing and packing often exhibit wide statistical variations, when evaluated at the microscale. Therefore, some localized microvolumes in the composite are always stressed more than others. The stress inhomogeneity is further enhanced by the inhomogeneity of the elastic properties of the composite constituents. The inhomogeneity of the stress field, coupled with the inhomogeneity of the strength and fracture properties of the reinforcing elements, the matrix, and the interface, lead to the gradual damage development in composites. As a result, the overall failure process in composites is often viewed as a process of formation, accumulation, and coalescence of damages of different types.

Many damage micromechanisms are observed in composites. For advanced fiber-reinforced composite laminates, the most typical damage mechanisms are matrix cracks, fiber breaks, and delaminations. The characteristic size of matrix cracks and fiber breaks is small. The characteristic size of delaminations is larger than that of the matrix cracks and the fiber breaks. As a result, the delamination damage is sometimes referred to as "macrodamage". However, even the delamination "macrocracks" are typically small in size when compared to the structural level damage. In this work, the word "macrodamage" will be used in a relative sense, in order to distinguish damage mechanisms that have characteristic sizes larger than those for typical matrix and fiber damage.

Studies of mechanisms and histories of damage in composites are necessary for better understanding of their ultimate failure and life. Theoretical analyses of damage evolution in composites were performed by many authors. A continuum damage mechanics approach was applied, for example, by Allen et al. (1987a, 1987b), Ladeveze et al. (1993), and Reifsnider et al. (1995). Elaborate analyses were conducted to evaluate the effects of damage on stiffness characteristics. The stochastic nature of gradual damage accumulation in composites was explicitly taken into account in statistical models of damage accumulation in composites developed, for example, by Rosen (1964), Zweben (1968), Tamuzh (1979, Harlow and Phoenix (1979), Batdorf (1982), Ovchinskii (1988), Phoenix (1993), Curtin (1993a, 1993b), Dzenis et al. $(1993,1994)$, and Dzenis and Joshi (1997). The models predicted gradual damage accumulation of different types under various loads. Development and verification of theoretical models of damage evolution in composites require experimental studies of damage development in these materials.

Experimental analysis of damage evolution in composites is not easy, however. A number of nondestructive evaluation (NDE) techniques were applied for this purpose. These included thermography, eddy current, optical holography, radiography, X-ray tomography, ultrasonic resonance, pulseecho, and through-transmission techniques (Pipes, 1979; Summerscales, 1987; Masters, 1992). The majority of these methods were capable of detecting larger individual flaws and delaminations in composites. However, the characteristic sizes of the matrix cracks, fiber breaks, fiber-matrix disbonds, and ply-damage induced delaminations were usually too small for these defects to be detected by the conventional NDE techniques. 


\subsection{Acoustic emission analysis of damage mechanisms}

A method that was shown capable of real time damage monitoring in composites is acoustic emission (AE) analysis (Yamaguchi et al., 1991). In this method, ultrasonic waves generated by the rapid release of elastic strain energy during damage events are detected and analyzed.

Two approaches to acoustic emission analysis were developed: parametric AE analysis and transient AE analysis. The bulk of the research on damage development in materials to date was performed by the parametric method. This method is based on the extraction of a number of parameters from individual AE signals. A typical AE signal is shown in Figure 1. Some of the AE parameters are defined in this figure, including signal amplitude, duration, rise time, decay time, and AE counts. Other parameters can be defined, for example average frequency, energy etc. Flags related to the signal shape, such as a multipeak flag, can also be defined.

Most AE systems operate in the parametric mode as follows. An ultrasonic wave caused by the damage event is detected by a piezoelectric AE sensor. The sensor converts the mechanical vibration into an analog signal. The signal is amplified by a preamplifier and digitized by the AE system. The system electronically extracts a number of parameters for each AE event. These AE parameters along with some additional information, such as time of arrival, and some external parameters, such as current load, are recorded into a parametric AE file. The AE signal itself if discarded in the parametric AE analysis. An advantage of the parametric analysis method is its simplicity. Modern AE systems provide powerful analysis and filtering capabilities for the AE parameters. AE histories, statistical distributions, and correlations can be generated and studied. Cluster analysis can be performed. AE location information can be extracted from the data from two or more sensors.

Parametric AE analysis was used to evaluate overall damage accumulation in composites by Williams and Reifsnider (1974), Awerbuch and Ghaffari (1988), Bakuckas et al. (1994), Ely and Hill (1995), Luo et al. (1995), and Shiwa et al. (1996). Williams and Reifsnider (1974) showed that the AE rate generally correlated with the rate of stiffness reduction due to damage. Numerous attempts to identify sources of the AE signals in composites were made. Different damage mechanisms were ex-

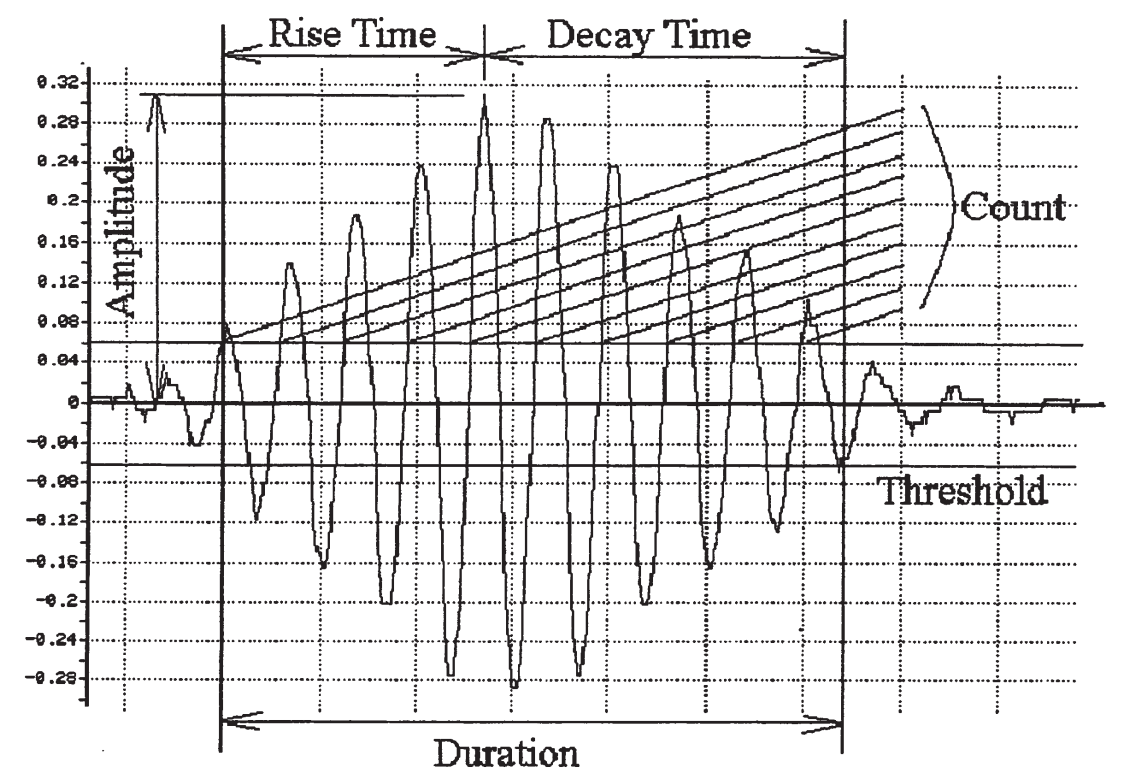

Figure 1. A typical acoustic emission signal. 
pected to produce AE signals with different AE parameters. Energy discrimination was used, for example, by Wevers et al. (1991). However, the attempts to apply single parameter filtering (single AE parameter threshold) to separate the damage mechanisms were largely unsuccessful due to overlap of the parametric ranges for different damage mechanisms (Kouvarakos and Hill, 1996). This parametric overlap is caused by the complexity and randomness of the damage process in composites. As mentioned above, similar microcracks do not occur simultaneously in all the similar microvolumes of the composite because the local microstructure and stress exhibit considerable variations. Similarly, the waves created by the microcracks of the same type are not necessarily the same. Variations in the crack location and orientation and complexity of the wave propagation process in composites (Chang and Sun, 1988; Gorman, 1992) further increase AE signal variability. Multiple reflections from internal and external boundaries and the associated mode conversions interfere with the source wave and change the AE parameters that are detected. All of the above results in statistical distributions of the AE parameters, even for the signals produced by similar microcracks. Depending on the type of damage and the width of these distributions, the AE from composites can sometimes result in AE parameter distributions exhibiting multiple peaks. Similarly, multiple clusters of signals (dense areas) can sometimes be observed on the AE parameter correlation plots. However, in practice, these multipeak distributions and clusters are rarely observed. Overall, the parametric AE analysis is capable of providing useful information on damage development in composites. However, the discrimination of damage mechanisms by this method is difficult to achieve due to the overlap of AE parameters caused by the complex damage and wave propagation processes in composites.

An alternative to parametric analysis is transient AE analysis. In transient analysis, full, digitized waveforms of the AE signals are recorded and analyzed. Transient analysis requires additional hardware compared to parametric analysis, i.e. a transient recorder. The type of AE sensors used in the analysis is also important for the transient analysis. Wideband sensors are usually preferred to resonant sensors. These sensors produce less distortion of the shape of the acquired signal. The results of the transient acquisition are recorded by the AE system into a transient AE file. This file typically contains a list of digitized AE signals (wave signatures) in the order they have been received by the system. Modern AE systems provide powerful advanced signal analysis capabilities. Wave frequency spectra can be calculated and analyzed. Additional AE parameters can be extracted, for example peak frequency, spectral moments, etc. Custom defined parameters can be calculated.

Transient analysis is a relatively new approach for damage analysis in composites. Recently, Ono and Huang (1996), Prosser et al. (1995), Kloua et al. (1995), and de Groot et al. (1995) applied the transient waveform analysis for AE source recognition. Methods of pattern recognition analysis and neural networks were used for the AE signal classifications. It was shown that, for composites, the characteristic signal shapes can be present in the overall AE signals and that these waveshapes can be associated with particular damage mechanisms. These recent results showed that the transient AE analysis method may provide more powerful and robust capability to discriminate between the damage mechanisms based on the full waveform analysis. A disadvantage of this method for the damage analysis in composites is the large amount of data that has to be acquired and analyzed. Composite materials typically accumulate a large number of microcracks of different types. This is especially true for long-term loads such as fatigue. The acquisition, storage, and analysis of full waveforms for all these signals is either impossible or impractical. In addition, the automated signal classification is not an easy task. It requires a thorough understanding of the classification algorithms and should generally be performed by experienced personnel.

Thus, the parametric and transient methods of AE analysis have advantages and disadvantages in regard to damage evolution studies in composites. Modern AE systems can provide both transient and parametric analysis capabilities. Such systems perform transient and parametric data acquisition 
simultaneously. The results are recorded in two data files, the parametric AE file and the transient AE file. Some systems have a capability to relate the transient records to the parametric records, thus providing means for simultaneous transient-parametric analysis. Such an analysis could theoretically combine the power of transient classification and the simplicity of parametric filtering. It would seem especially advantageous for studies of damage evolution in composites.

A hybrid transient-parametric approach to separate overall AE histories into the histories for different damage micromechanisms was recently proposed by Dzenis and Qian (1998). The method was based on the combination of the transient AE waveform analysis and multiparameter filtering. The method was applied to damage evolution analysis of a simple unidirectional composite material. The objective of the present paper is to further develop this method and to apply it to a wider range of composite materials. Four different composite systems were analyzed simultaneously: two unidirectional composites, $[0]_{8}$ and $[90]_{16}$, a cross-ply composite $[0 / 90]_{3 S^{\prime}}$ and an angle-ply composite $[ \pm 45]_{4 \mathrm{~S}}$. A transient $\mathrm{AE}$ analysis was performed and three characteristic waveforms were classified, as detailed in Section 3.3. The multiparametric AE spaces were then analyzed and the regions occupied by different waveforms were identified. The evolution histories for different waveforms were extracted from the overall acoustic emission by multiparameter filtering. The damage mechanisms responsible for the characteristic AE waveforms were identified by comparisons with observed damage mechanisms in different composites. The results indicated that the multiparameter filters can be transferred with reasonable reliability between distinct composite lay-ups within the same material family.

\section{Experimental}

\subsection{Materials and manufacturing}

Composite materials were manufactured from Hexcel T2G-190-12-F263 graphite-epoxy unidirectional prepreg tape. Laminated panels were assembled following hand lay-up procedure and cured in a twochamber press-clave under controlled temperature, pressure, and vacuum environments. The manufacturer recommended curing cycle was applied. Four composite lay-ups were used in this study: two unidirectional composites, $[0]_{8}$ and $[90]_{16}$, a cross-ply composite $[0 / 90]_{3 S}$, and an angle-ply composite $[ \pm 45]_{45}$. The cured panels were tabbed using strips of a commercial glass fiber woven composite. The tabbing prevented premature failure of composites and reduced acoustic noise from grips. Rectangular composite specimens were then machined from the tabbed panels by a high-speed diamond saw. The specimen length was in the range from 200 to $250 \mathrm{~mm}$. The specimen width was $25 \mathrm{~mm}$ for the $[90]_{16}$ composite, $20 \mathrm{~mm}$ for the $[ \pm 45]_{4 S}$ composite, and $15 \mathrm{~mm}$ for the $[0]_{8}$ and $[0 / 90]_{3 S}$ composites. The specimen thickness was determined by the lay-up and varied from $1.48 \mathrm{~mm}$ for the unidirectional $[0]_{8}$ composite to $2.86 \mathrm{~mm}$ for the angle-ply composite.

\subsection{Mechanical testing}

Tensile mechanical testing was performed by a servohydraulic MTS testing machine digitally controlled with an Instron test control and data acquisition system. All quasi-static tests were performed under stroke control with Instron 8500 software. The displacement rates used were $0.5 \mathrm{~mm} / \mathrm{min}$ for the $[0]_{8}$ composite, $0.1 \mathrm{~mm} / \mathrm{min}$ for the $[90]_{16}$ composite, and $0.3 \mathrm{~mm} / \mathrm{min}$ for the laminated composites. A uniaxial MTS 632 extensometer and a biaxial Instron 2620 extensometer were used for strain measurement. The axial gauge length was $25 \mathrm{~mm}$. The specimens were clamped with serrated wedge action grips. Special care was exercised while installing specimens within the grips to ensure alignment. Additional alignment was provided by a Satec spherical alignment coupling. 


\subsection{Acoustic emission testing}

A two-channel AMS3 AE system by Vallen Systeme, GmbH was used for acoustic emission analysis. Each AE channel was connected to a preamplifier attached to an AE sensor. AE events were acquired by the sensor as analog signals. They were preamplified and converted into digital signals by an A/ $\mathrm{D}$ converter. The AE signal parameters were then extracted by the system, augmented with time of arrival and external parameters (load and strain), and recorded in a parametric AE file. The system was equipped with a transient recorder. In parallel with the AE parameter acquisition, full, digitized waveforms of the AE events were acquired by the transient recorder and recorded in a separate transient AE file. Each AE waveform was assigned a unique transient index. This index was stored as one of the parameters in the parametric AE record, providing the capability to establish the correspondence between the waveforms and the parametric records in the two files.

Two wide-band, high fidelity B1025 AE sensors by Digital Wave were used in the analysis. The sensors were mounted on the specimen by means of tape. Vaseline was used as a coupling agent between the sensor and the composite surface. The effect of sensor attachment force was investigated using an ultrasonic pulser. An imitation AE signal was generated by the pulser, transmitted from one sensor to another, and analyzed by the AMS3 system. It was found that the variation of parameters of the transmitted signals became saturated when the attachment force reached the level of about $10 \mathrm{~N}$. Consequently, a force of $10 \mathrm{~N}$ was used in all AE experiments.

The AE gauge zone (the distance between the AE sensors) was $60 \mathrm{~mm}$ for the $[90]_{16}$ composite and $80 \mathrm{~mm}$ for all other composites. The AE source location analysis was performed on the incoming signals and the signals originating outside the acoustic gauge zone were filtered out in order to reduce the acoustic noise generated by the testing machine and grips.

A $34.5 \mathrm{~dB}$ system gain and a $40.5 \mathrm{~dB}$ threshold were used for the AE acquisition. The AE data acquisition was initiated simultaneously with mechanical loading. The acoustic emission was thus recorded from the beginning of the test to the final failure of the specimen. The information on load and strain was continuously fed from the Instron 8500 system to the AMS3 system. This information was stored in the parametric AE record and allowed to correlate the AE parameters with the load and strain at the time the AE signal was produced.

As a result of each test, two data files were generated for each specimen, the parametric file and the transient file. The former contained a list of parametric data records. The latter contained a list of digitized waveforms. The AMS3 software provided powerful filtering and waveform analysis capabilities that were used for AE data analysis after the tests were completed.

\section{Results and discussion}

\subsection{Mechanical response}

Several specimens of each of the aforementioned types were tested in tension. Both biaxial and uniaxial extensometers were used. The quasi-static response of the representative composite specimens is shown in Figures 2 and 3.

Figure 2 shows the stress-strain diagrams of the unidirectional $[0]_{8}$ and $[90]_{16}$ composites. Both tests were performed with the biaxial extensometer. The positive strain branches of the stress-strain diagrams in Figure 2 correspond to the longitudinal tensile strain. The negative strain branches correspond to the Poisson contraction in the transverse to load direction. The stress-strain diagrams of the unidirectional composites were almost linear. The slight nonlinearity (stiffening) observed in Figure 2(a) is typical for unidirectional graphite fiber reinforced composites and is due to the nonlinear fiber response. A slight nonlinearity (softening) in Figure 2(b) may be due to damage accumulation. The 
(a)

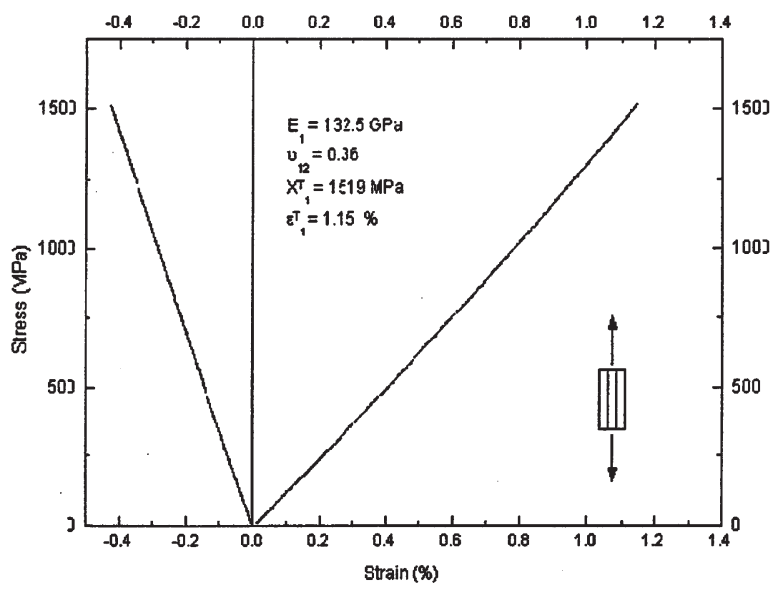

(b)

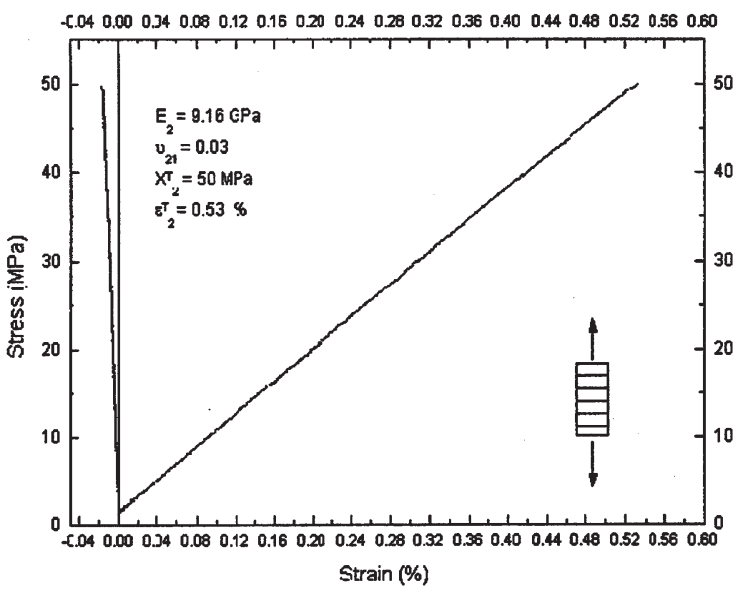

Figure 2. Quasi-static tensile response of unidirectional composites: (a) $[0]_{8}$ and (b) $[90]_{16^{\prime}}$, showing both longitudinal and transverse strains.

elastic constants and the ultimate properties of the unidirectional specimens, extracted from the diagrams, are shown in the figure.

Figure 3 presents the stress-strain diagrams for the laminated composite specimens. The angleply composite (Figure 3a) exhibited strong nonlinearity. The reverse of the stress-strain diagram at high loads (the decrease of stress with the increase of strain) is typical for these composites tested under displacement control. The two branches of the plot for the $[ \pm 45]_{4 S}$ specimen were almost symmetric due to the fact that both the +45 and the -45 plies were loaded in pure shear in their respective material axes. Figure 3(b) presents the axial stress-strain diagram for the cross-ply composite obtained with the uniaxial extensometer. Note that the angle-ply and cross-ply composites represent the same laminated composite material tested in two different directions. Comparison of Figure 3(a) and 3(b) showed strong anisotropy of mechanical properties of this composite. Both strength and stiffness of the cross-ply composite (Figure 3(b)) were higher than the strength and stiffness of the angle-ply composite. The stress-strain plot for the cross-ply composite specimen was almost linear to failure. 
(a)

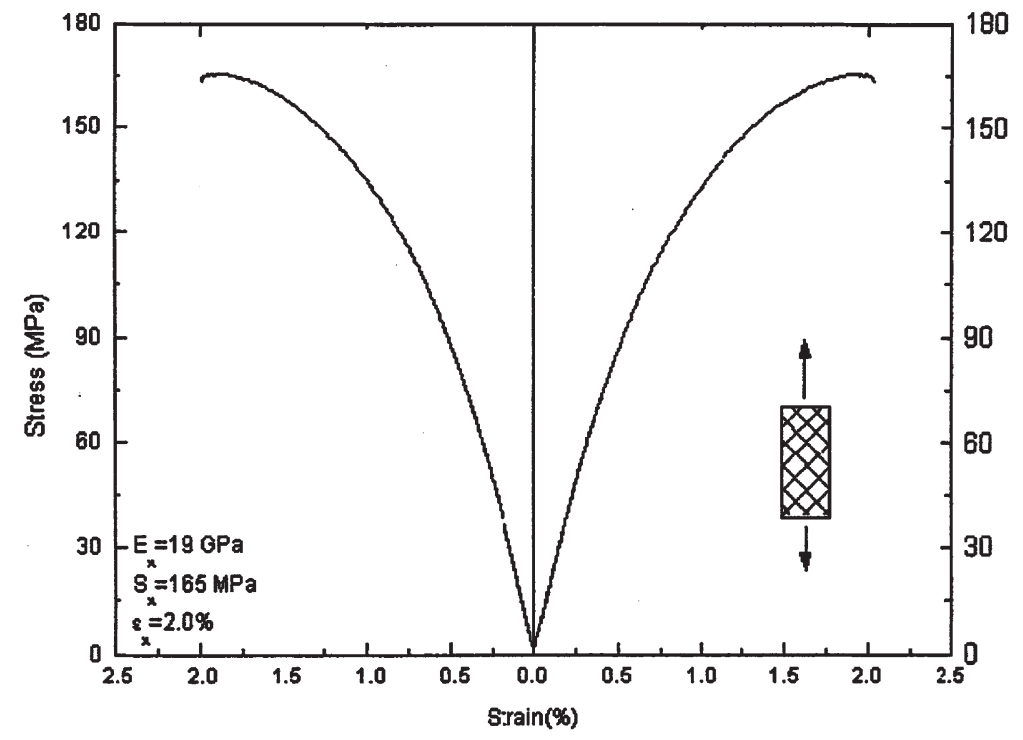

(b)

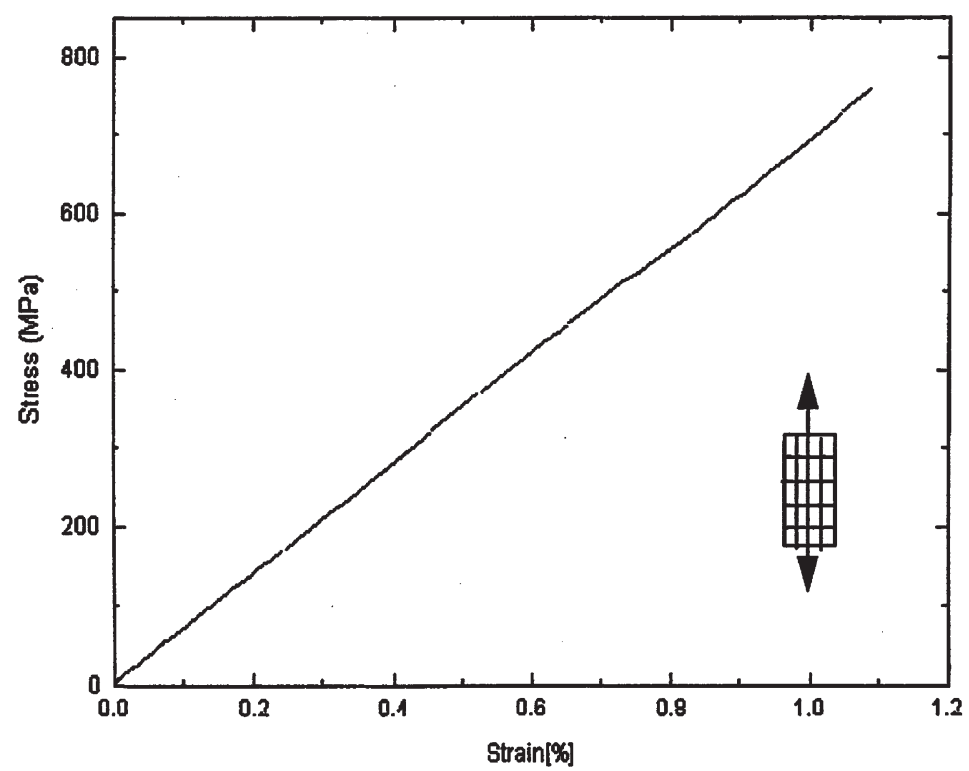

Figure 3. Quasi-static tensile response of laminated composites: (a) $[ \pm 45]_{4 S^{\prime}}$ showing both longitudinal and transverse strains, and $(\mathbf{b})$ the longitudinal strain for $[0 / 90]_{35}$.

Little visible damage was detected in all but the cross-ply laminate prior to failure. On-line observations revealed matrix cracking in the $90^{\circ}$ plies and some edge delamination in the cross-ply composite. Edge delamination is typical for these composites and is caused by the high inter-laminar stresses due to the mismatch of the Poisson coefficients of the 0 and 90 plies. 
(a)

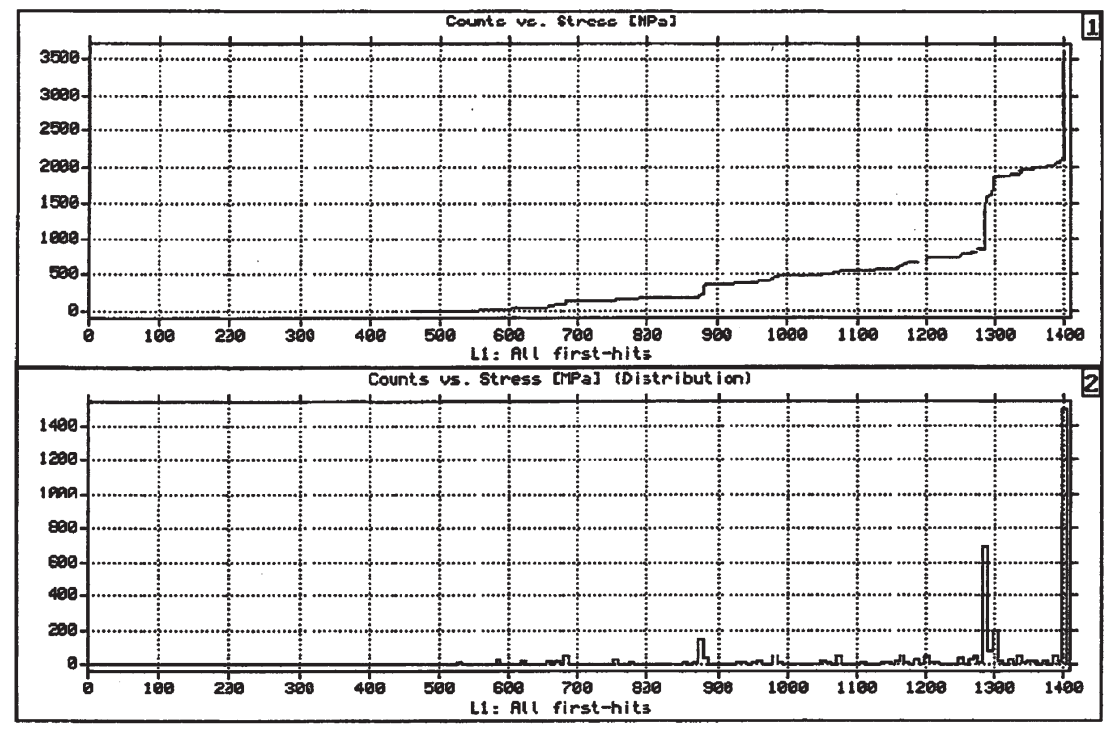

(b)

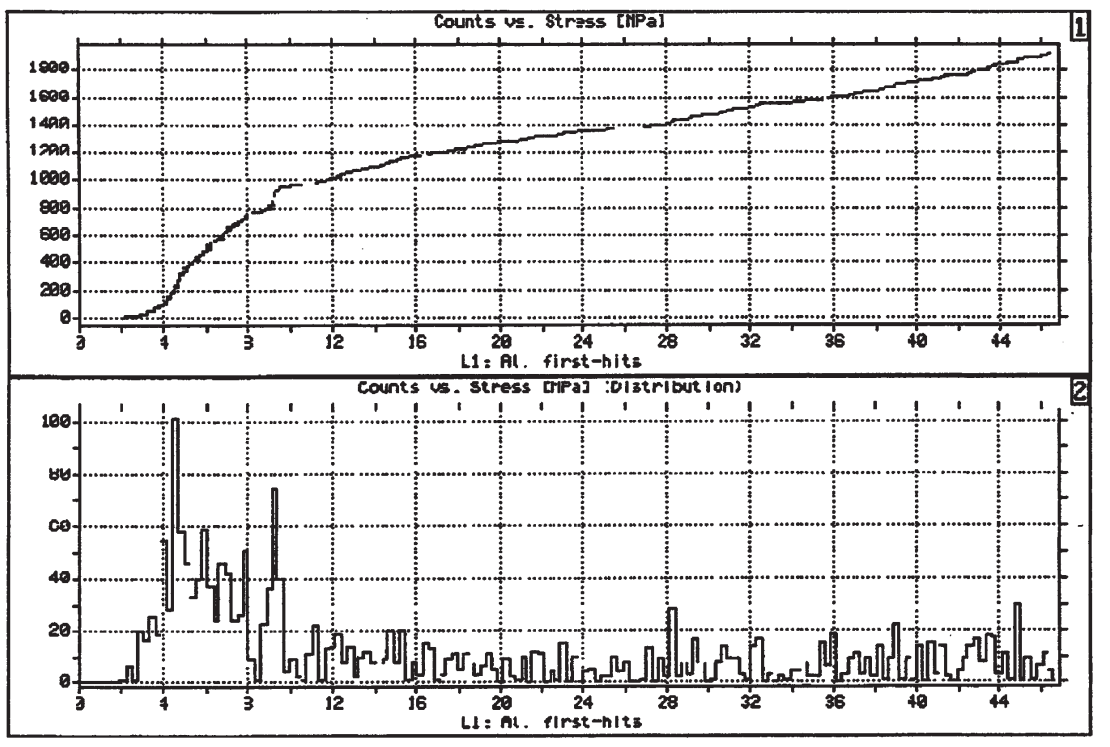

Figure 4. Overall history of AE in unidirectional composites: (a) $[0]_{8}$ and (b) $[90]_{16}$.

\subsection{Parametric acoustic emission analysis}

\subsubsection{Overall acoustic emission histories}

Overall stress histories of the AE counts for the unidirectional and laminated composites are shown in Figure 4 and Figure 5, respectively. In these history plots, the AE counts are presented as a function of tensile stress. The top plots that were marked 1 represented the cumulative count histories. The bot- 
(a)

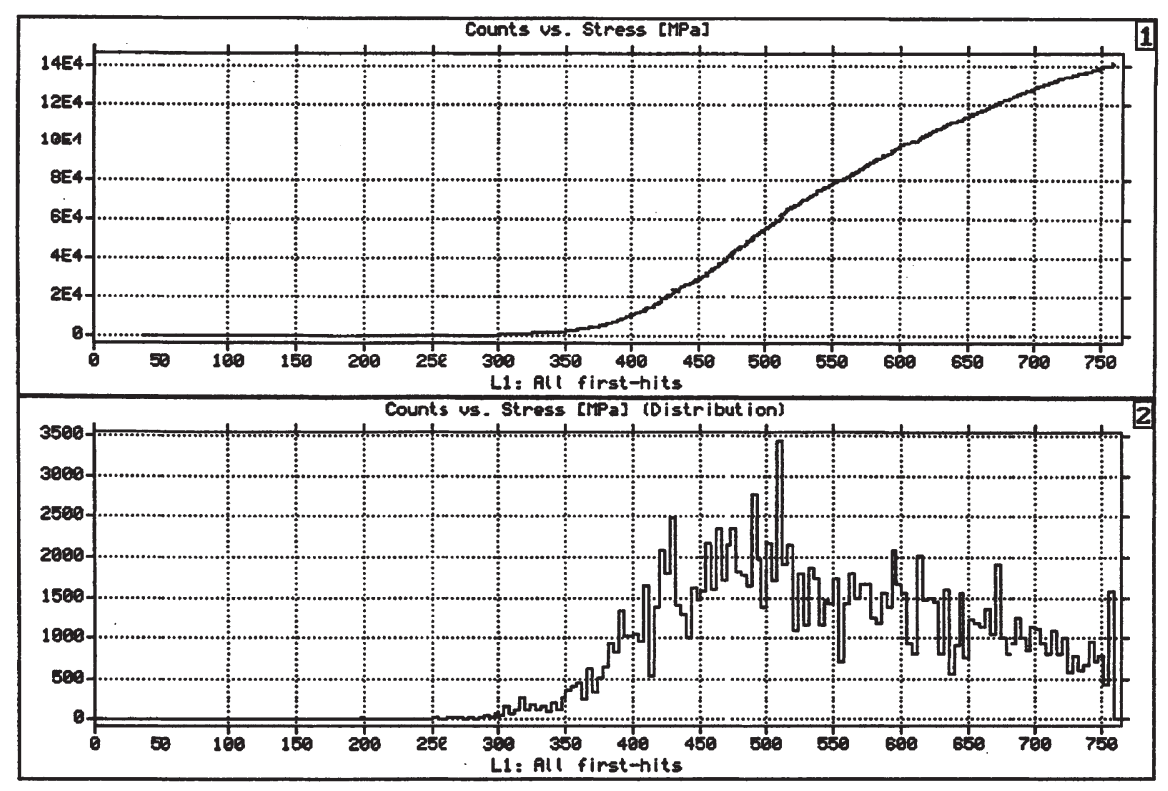

(b)

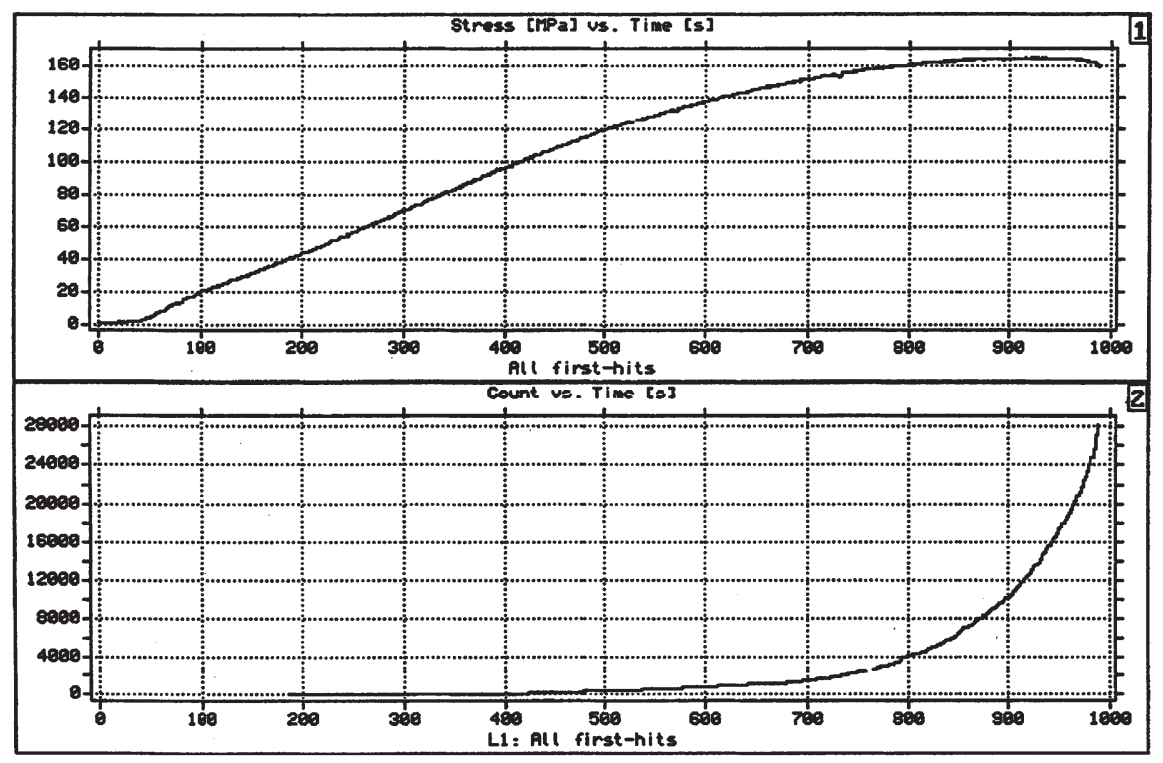

Figure 5. Overall history of AE in laminated composites: (a) $[0 / 90]_{3 \mathrm{~S}}$ and (b) $[ \pm 45]_{4 \mathrm{~S}}$.

tom plots that were marked 2 represented the histories of the AE accumulation rates. The AE counts defined in Figure 1 provide a convenient measure of the overall AE activity of the specimens.

The acoustic emission in the unidirectional $[0]_{8}$ specimen (Figure $4(\mathrm{a})$ ) started at about $40 \%$ of the specimen ultimate load and accumulated unevenly to failure with most of the emission generated at 
higher loads. Two jumps were observed at the stress levels around 900 and $1300 \mathrm{MPa}$. A final jump was observed near the maximum load. In between these jumps, the AE accumulated with a slowly increasing rate. The unidirectional $[90]_{16}$ specimen (Figure $4(\mathrm{~b})$ ) showed different AE behavior. The AE started to accumulate early in the test, at about $10-15 \%$ of the ultimate load. The accumulation rate (plot 2 in Figure 4(b)) reached a maximum, decreased, and then stayed almost constant to failure.

The laminated composites (Figure 5) produced considerably more AE indicating more extensive damage development in these materials. In the case of the cross-ply composite (Figure 5a), the emission started at about $50 \%$ of the ultimate load. The accumulation rate grew rapidly at the beginning of the damage process and reached the maximum at about $65 \%$ of the ultimate load. The damage process then showed signs of saturation with the accumulation rate decreasing monotonically to failure.

Due to the nonlinear stress-strain response of the angle-ply composite (Figure 3(a)), the cumulative history of the AE counts for this material was studied as a function of time (plot 2 in Figure 5(b)) rather than stress. The stress-time dependence is shown in plot 1 of Figure 5(b), for reference. The analysis showed that the AE accumulation in this composite started at about $70 \%$ of maximum load. Subsequently, the accumulation rate accelerated monotonically to failure. It is interesting that the accumulation rate continued to increase even when the load started to decrease upon approaching failure. Load decrease in a displacement controlled experiment indicates extensive damage development in composite.

Both laminated composites exhibited more extensive damage due to the more inhomogeneous stress fields in these materials composed of strongly anisotropic plies with different fiber orientations. As a result, smoother cumulative AE histories were observed.

\subsubsection{Parametric distributions and correlations}

Results of the parametric AE analyses are shown in Figure 6 and Figure 7. Each graph contains four plots marked 1-4 in their upper right corners. The histogram plots 1-3 represent the statistical distributions of the duration (1), rise time (2), and amplitude (3) of the AE signals acquired during a particular test. The count numbers on the vertical axes in these plots represent the frequency of occurrence of the AE signals with a particular value of the AE parameter shown on the horizontal axis. The correlation plot 4 represents the correlations of the amplitude (vertical axis) and duration (horizontal axis) of the AE signals. In these plots, each dot represents an individual AE event. The parametric scales in all plots in Figures 6 and 7 are kept the same for easier comparisons.

The analysis of the unidirectional specimens (Figure 6) showed that, when compared with the [90] $]_{16}$ composite, the $[0]_{8}$ composite (Figure 6(a)) generally produced signals with higher duration and amplitude, but lower rise time. However, the ranges of variation of the AE parameters were wide for this composite. The analysis of the laminated specimens (Figure 7) was more meaningful because of the larger numbers of signals produced by these composites. The cross-ply specimen (Figure 7(a)) exhibited duration and amplitude histograms with two peaks. The rise time of the signals from this specimen was widely distributed, however. The correlation plot showed some amplitude-duration correlation for the signals with longer duration. The results of the similar analysis for the angle-ply composite (Figure 7(b)) showed that this specimen exhibited a weak second peak on the duration histogram but did not exhibit multiple peaks on the amplitude histogram. In addition, the positions of the major peaks in all histograms shifted compared to the corresponding positions of the peaks for the cross-ply composite.

As mentioned above, multiple peaks in the distribution histograms can be caused by signal produced by different damage mechanisms. The two peaks on the duration histogram of the cross-ply composite (Figure 7(a)) are separated by the threshold duration around $1000 \mu \mathrm{s}$. This threshold was used by Dzenis and Qian (1998) to distinguish the characteristic long duration signals in the unidirectional composite. These signals were associated with the "macroscopic" damage, namely with the longitudinal splitting in the $[0]_{8}$ composite. To understand the nature of these signals in the cross-ply composite (Figure 7(a)), a duration filter was applied. The signals with durations above $1000 \mu$ s were extracted and the parametric 
(a)

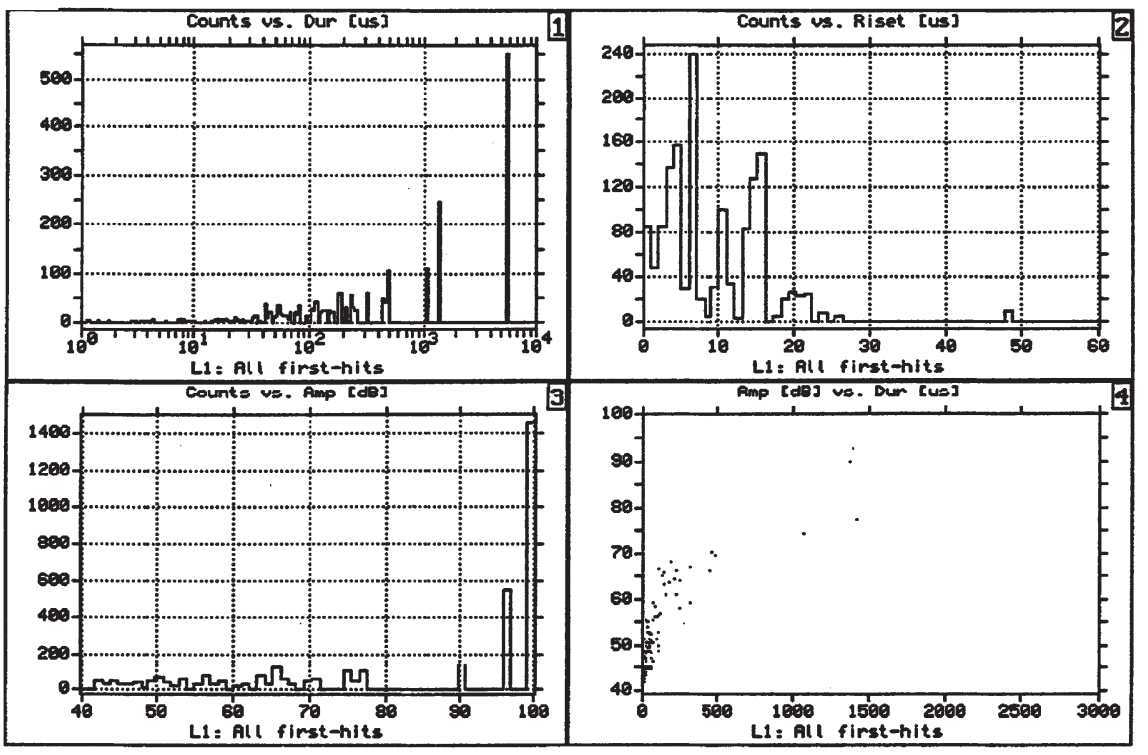

(b)

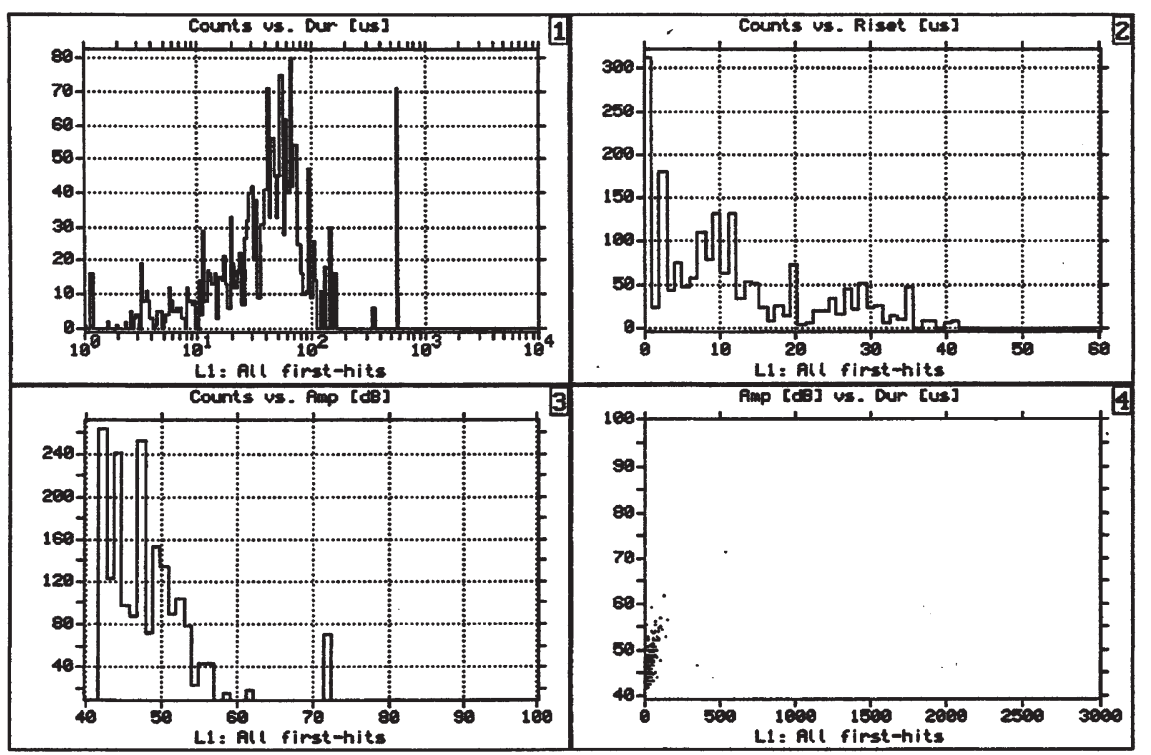

Figure 6. AE parameter distributions and correlations for unidirectional composites: (a) $[0]_{8}$ and (b) $[90]_{16}$.

analysis, similar to the analyses in Figure 6 and Figure 7, was performed. The results of this analysis are shown in Figure 8. It is seen that the signals with long duration accounted for the second peak in both duration and amplitude histograms (compare plots 3 in Figure 7 and Figure 8). However, the rise time of these signals was distributed over a very wide range. The high duration signals were assumed by other authors to be associated with "macroscopic" damage in composites. The fact that "macroscopic" delaminations were observed in the cross-ply composite corroborated this assumption. 
(a)

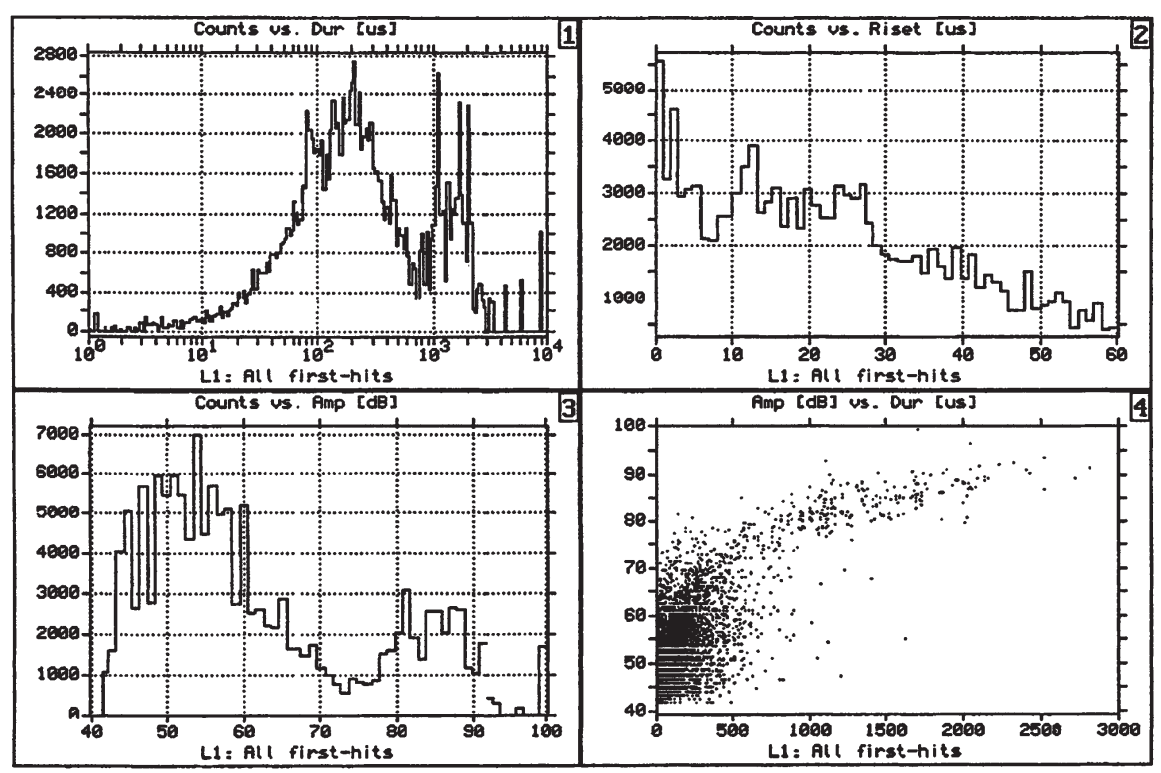

(b)

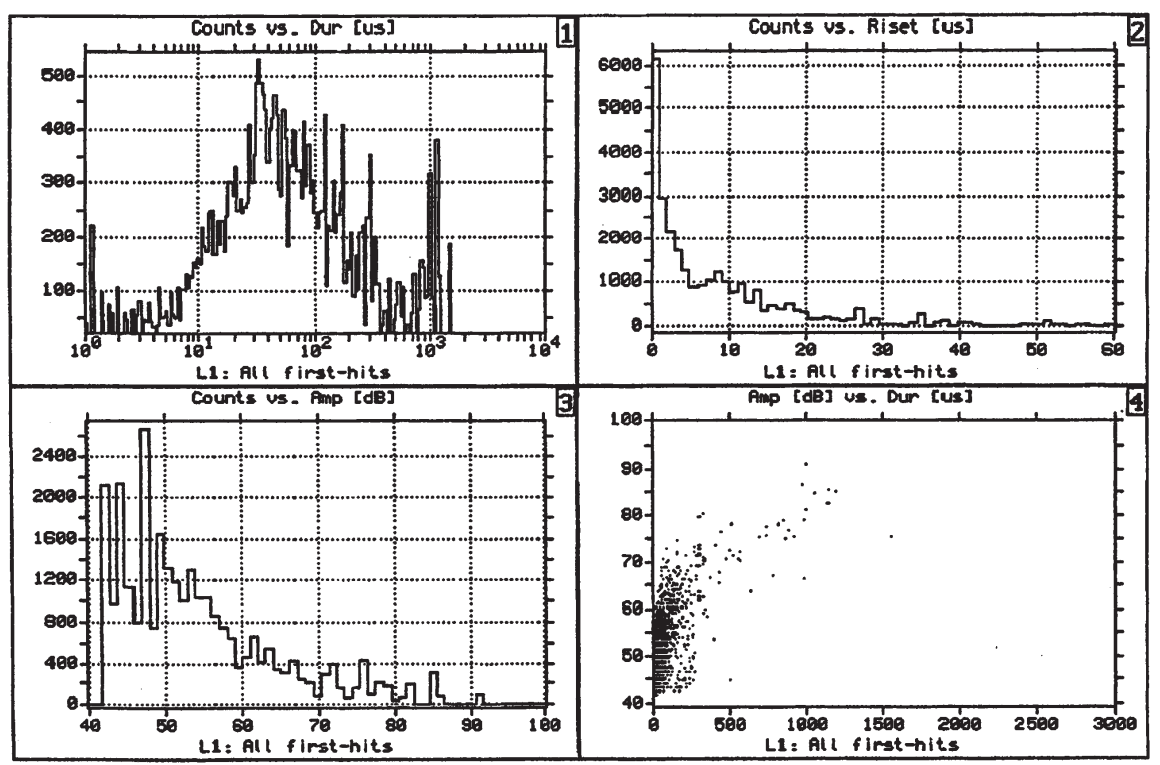

Figure 7. AE parameter distributions and correlations for laminated composites: (a) $[0 / 90]_{3 S}$ and (b) $[ \pm 45]_{4 S}$.

Overall, the parametric AE analysis provided useful information on damage development in composites. The damage started to develop early in the specimens tested and the accumulation rates increased with loading. One of the composites (the cross-ply composite) exhibited two double-peak parametric histograms. These peaks correlated with each other and those that corresponded to the higher duration could be associated with the "macroscopic" damage in the form of delaminations. 


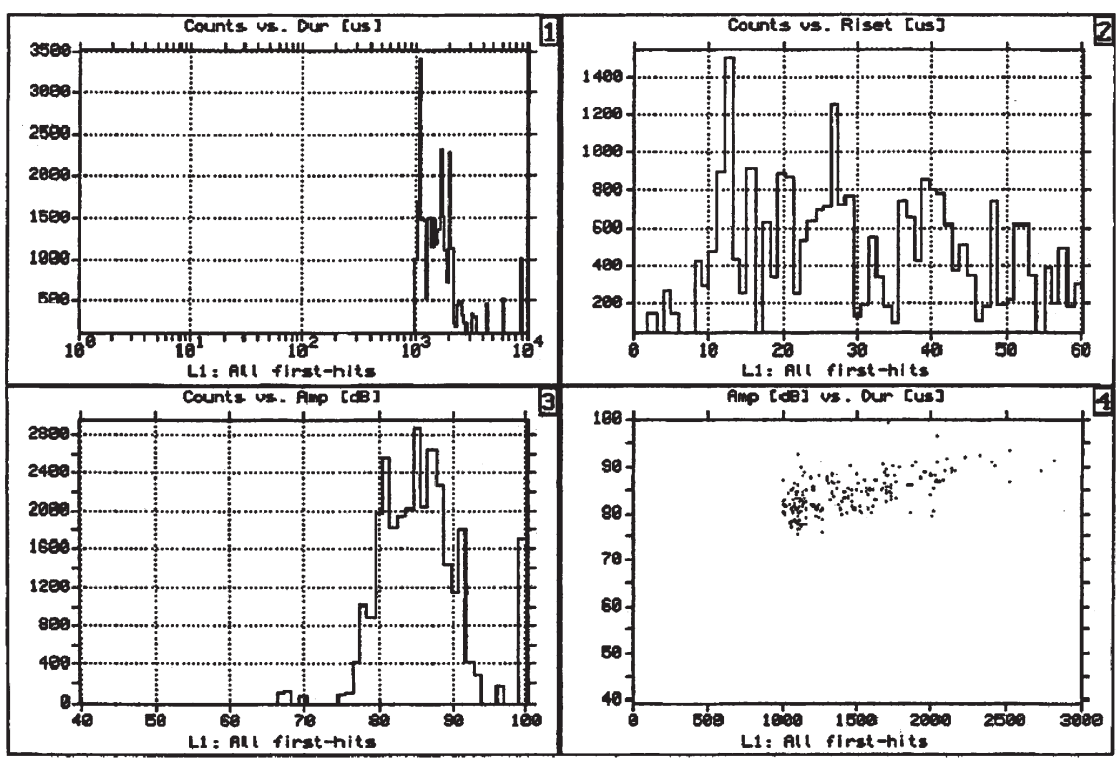

Figure 8. Filtered AE parameter distributions and correlations of signals exceeding $1000 \mu$ s durations for the $[0 / 90]_{3 S}$ composite.

Apart from these two double-peak histograms, all other histograms exhibited wide statistical distributions of the AE parameters with no discernible borders (thresholds) between the signals from different damage modes. The correlation plots did not produce discernible clusters of signals. Other methods are therefore needed to extract the AE from the other damage mechanisms, such as the fiber and matrix cracks.

\subsection{Transient acoustic emission analysis}

Transient AE analysis of the signals recorded in the quasi-static tests was performed by the AMS3 system. The frequency spectra of the signals were calculated by the fast Fourier transform (FFT). The transient AE waveforms along with their FFT spectra were screened in a search for characteristic AE waveforms. The screening revealed that three typical waveforms were frequently produced by composites (Figure 9). Classification was based primarily on the shape of the frequency spectrum. The A type waveforms had low amplitude, medium to long rise time, and the peak frequency between 100 and $220 \mathrm{kHz}$. The B type waveforms had medium to high amplitude, shorter rise time, and the peak frequency between 300 and $700 \mathrm{kHz}$. The $\mathrm{C}$ type waveforms had a very wide frequency spectrum and a very long duration. For all the foregoing types, the shape of the frequency spectrum was more robust and exhibited less variability than the signal parameters. The characteristic waveforms (Figure 9) were first found by the analysis of unidirectional composites (Dzenis and Qian, 1998), and similar characteristic waveforms were observed in laminated composites. The signals of the three types described above accounted for a substantial portion of the overall AE. However, some signals in the overall AE could not be classified. The latter fact is due to the diversity and complexity of the damage and wave propagation phenomena in composites.

Theoretically, the histories of the AE with different characteristic waveforms can be extracted from the transient records. However, the amount of the AE in composites is often too large to make this analysis practical. This is especially true for the damage analysis of composites under fatigue. Dzenis and Qian (1998) used multiparameter AE filters to extract the histories for different AE waveforms. 
(a)

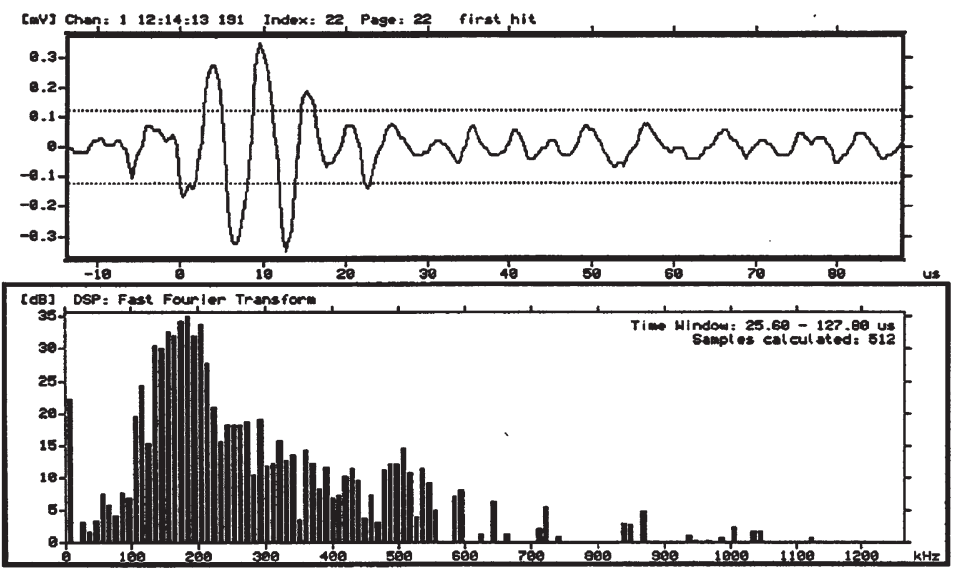

(b)

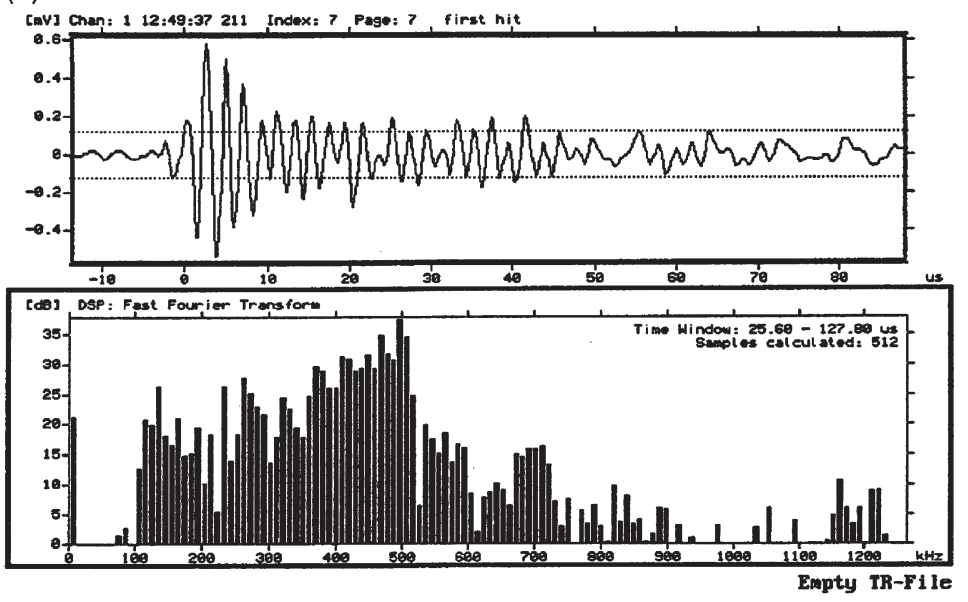

(c)
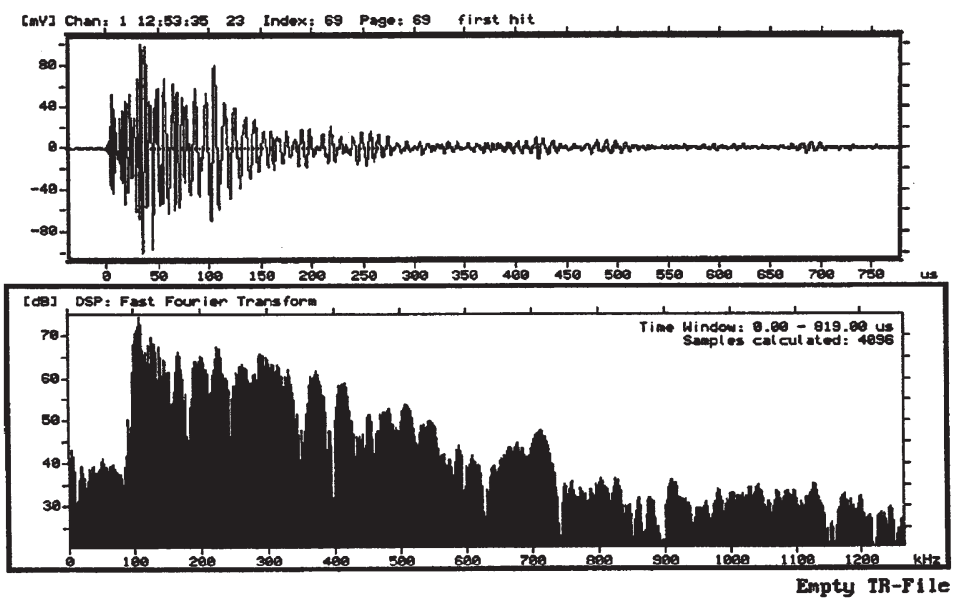

Figure 9. Characteristic AE waveforms and their frequency spectra: type A (a), B (b), and C (c) signals. 
Application of this method to the analysis of unidirectional composites is reviewed in Section 3.4 below. Application of the method to the analysis of laminated composites is described in Section 3.5.

\subsection{Evolution histories of microdamage in unidirectional composites}

\subsubsection{Identification of multiparametric regions for characteristic waveforms}

A correlation was established between the parametric and transient records by using the transient index as explained above. The analysis of the $[0]_{8}$ composite showed that the majority of the signals with durations above $1000 \mu$ s belonged to the $C$ type waves. The $C$ type signals were, therefore, extracted by the duration filtering. However, the signals of types A and B had overlapping parameters. The analysis showed that no single AE parameter could be used to discriminate between these signals.

An attempt was made to find a multiparametric space that would show a separation of the A and B type signals. Several parametric spaces were checked for this purpose. Correlation plots similar to the ones in Figures 6-8 (plots 4) were constructed and analyzed. Using transient indices, the locations of the signals with a particular waveform were identified on the correlation plots. The analysis showed that the best separation of the A and B type signals was in the amplitude and rise time space (Figure 10). Figure 10 shows the parametric areas occupied by the signals of these two types on the correlation plots for the unidirectional composites. The horizontal and vertical axes in these plots represent the signal rise time and amplitude, respectively. The same regions were identified for the $[0]_{8}$ and $[90]_{16}$ composites. For both composites, the demarcated regions contained the signals of the particular assigned type and some unclassified signals. No signals of the opposite type were observed in these regions. The narrow area between the two above-mentioned regions contained the waveforms of both types, as well as other, unclassified signals, and was, therefore excluded. The regions in Figure 10 were used for the parametric analysis of histories of the characteristic AE signals.

\subsubsection{Classified acoustic emission histories for unidirectional composites}

The regions in Figure 10 were subdivided into rectangular boxes and the multiparameter filters were defined (Dzenis and Qian, 1998). The multiparameter filtering capability of the AMS3 system was then utilized to extract the AE histories for the A and B type waveforms. Note that the C type signals were extracted prior to multiparameter filtering by the simple duration filter. The results of the analysis are shown in Figure 11.

Figure 11 (a) presents the classified AE histories for the $[0]_{8}$ composite. The A type signals initiated first, at a very low stress. Subsequently, at about $50 \%$ of ultimate stress, type B signals began to accumulate, with type $C$ signals developing last. The latter type started to accumulate shortly after the beginning of the B type emission. The A and B type signals accumulated relatively uniformly, with several small jumps observed on the B type curve. However, the $C$ type signal accumulation was rather abrupt with several substantial jumps observed at different loads. Comparisons with the overall $\mathrm{AE}$ history in Figure 4(a) showed that the jumps in the overall history were due to the $C$ type signals. Some correlation could be observed between the history plots for the B and C type AE signals.

Figure $11(\mathrm{~b})$ presents the classified AE histories for the $[90]_{16}$ composite. The A type signals initiated at low stress and dominated throughout this test. A small number of the B type signals were also accumulated. No C type signals were detected in the $[90]_{16}$ specimen.

\subsubsection{Correlation of characteristic waveforms with damage mechanisms}

The ultimate AE content in the unidirectional composites is summarized in Table 1 . Note that the sums in the table are less than $100 \%$. This is due to the fact that signals with parameters falling outside the demarcated regions for the A and B type signals in Figure 10, were excluded from the analysis.

One expects the failure of the $[90]_{16}$ composite to be dominated by matrix damage with little or no damage of the other types. The $[0]_{8}$ composite, on the other hand, is expected to develop both fi- 
(a)

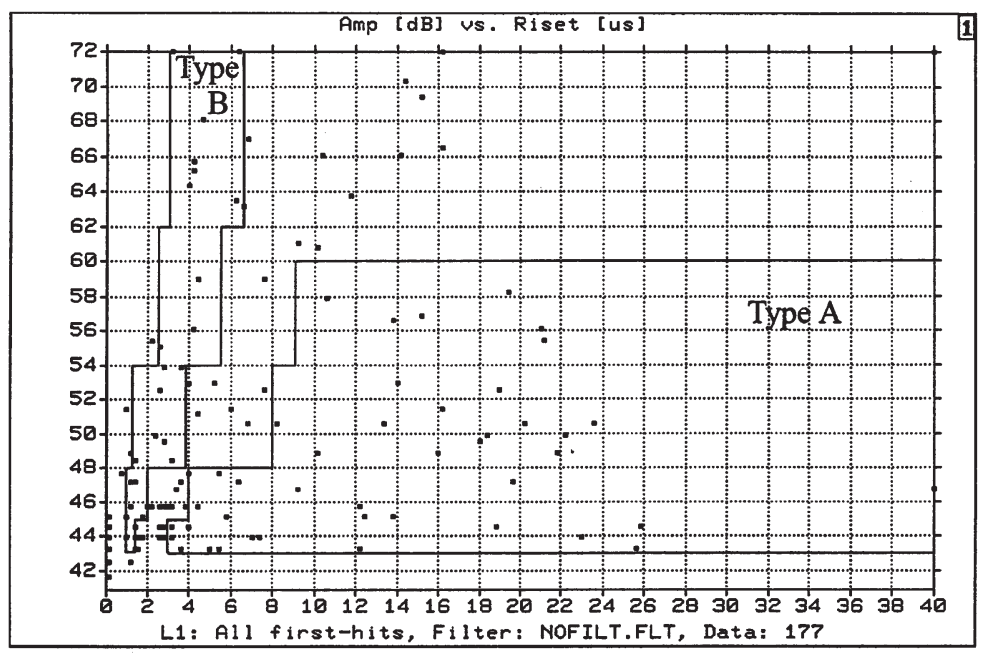

(b)

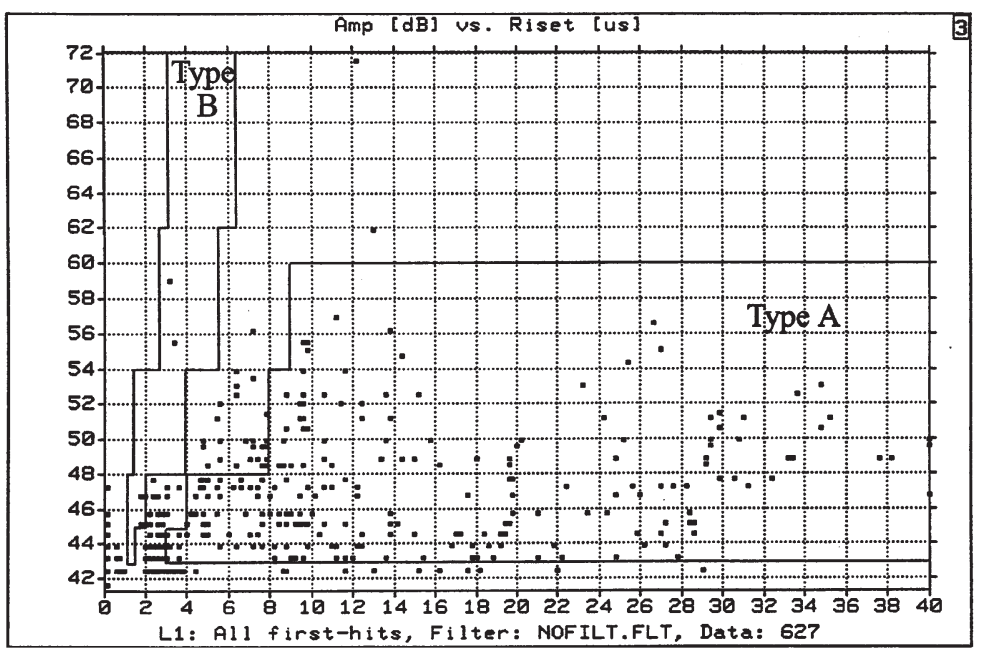

Figure 10. Amplitude and rise time correlation for unidirectional composites: (a) $[0]_{8}$ and (b) $[90]_{16}$.

ber breaks and matrix cracks. In addition, unidirectional composites loaded in the fiber direction often develop longitudinal splitting cracks along the fiber direction. The photographs of the failed unidirectional specimens analyzed in this work are shown in Figure 12. The photographs corroborate the expected damage modes in the composites described above. Correlations of the observed damage mechanism in the unidirectional composites with the classified AE histories and the ultimate AE content in these materials (Table 1) suggest that the A type AE signals can be attributed to matrix cracking, the B type signals to fiber breaks, and the C type signals to "macrodamage" in the form of splitting along the fiber direction.

The classified AE histories in Figure 11 thus confirm that the $[90]_{16}$ composite (Figure 11(b)) produced mostly matrix damage. Although, some isolated fiber breaks were also detected, their number was very low. No "macrodamage" was observed in this composite. The results correlate well with the 
(a)

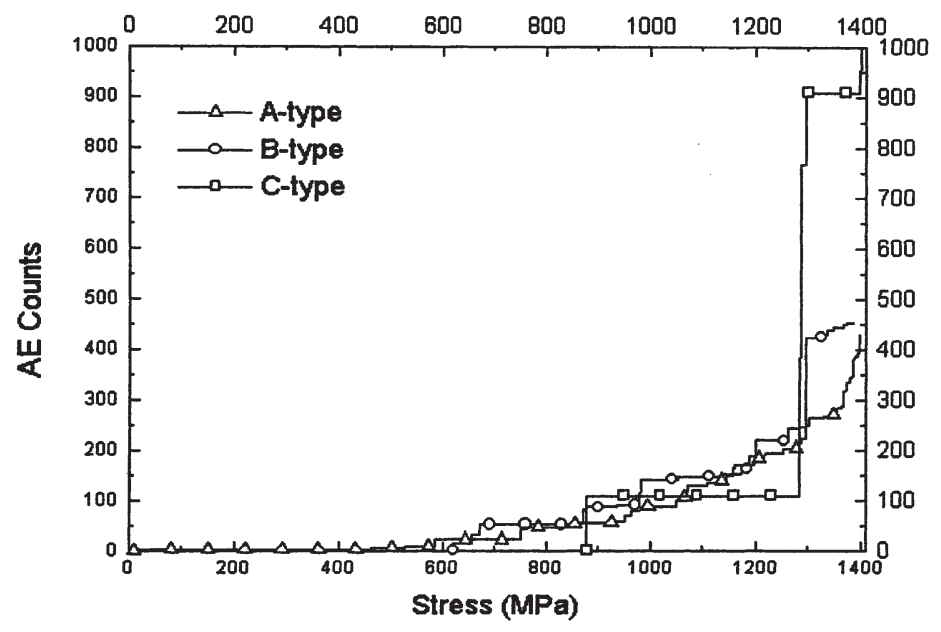

(b)

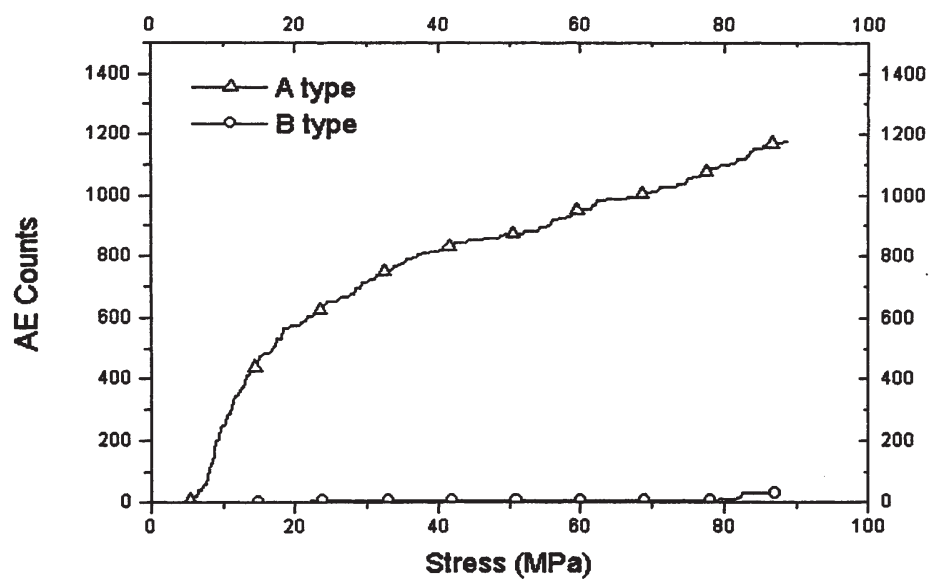

Figure 11. Classified AE histories for unidirectional composites: (a) $[0]_{8}$ and (b) $[90]_{16}$.

Table 1. Ultimate AE content for unidirectional composites

\begin{tabular}{clll}
\hline Composite & A & B & C \\
\hline$[0]_{8}$ & $20 \%$ & $22 \%$ & $48 \%$ \\
{$[90]_{16}$} & $70 \%$ & $1.4 \%$ & None \\
\hline
\end{tabular}

failure mode in Figure 12(b). The damage development in the $[0]_{8}$ composite was more complex. It started with a few isolated matrix cracks, which developed at a very low load. The fiber breaks started to accumulated at approximately $50 \%$ of the ultimate stress and continued to accumulate till the final failure. Soon after the fiber fracture occurred, "macrodamage" in the form of splitting began to develop. The macrodamage progressed unevenly with several extensive damage events that were detected by the overall AE history for this composite (Figure 4(a)). Shortly before the final failure, an 
(a)

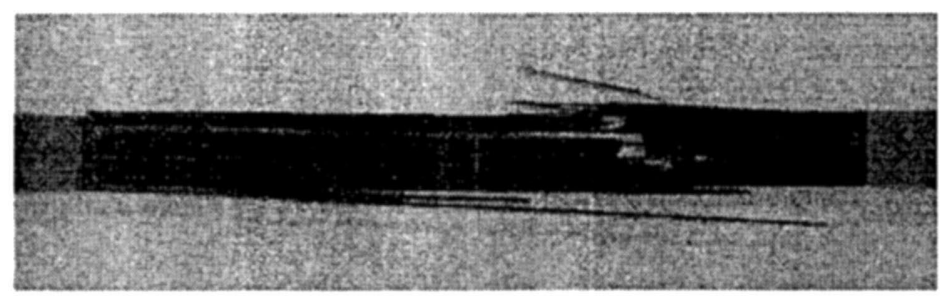

(b)

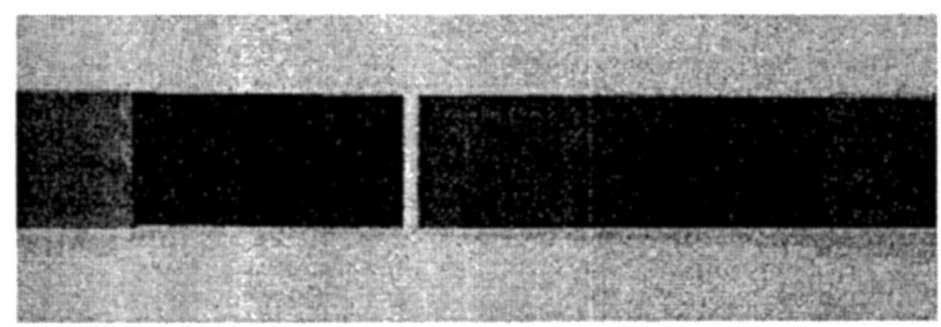

Figure 12. Failed specimens of unidirectional composites: (a) $[0]_{8}$ and (b) $[90]_{16}$.

extensive splitting event occurred that was followed by a substantial fiber breakage. The final failure of this composite could therefore be associated with the two other interacting damages modes: the fiber breaks and the longitudinal splitting. This correlates well with the damage observed in Figure 12(a).

\subsection{Evolution histories of microdamage in laminated composites}

\subsubsection{Classified acoustic emission histories for laminated composites}

The transient analysis of the AE acquired from the laminated composites showed that the characteristics waveforms observed in the unidirectional composites were also observed in both laminated composites. An attempt was therefore made to use the multiparameter filters developed for the unidirectional composites to extract the classified AE histories for the laminates. The $C$ type signals were separated first by the duration filtering, and types A and B signals were subsequently extracted by the multiparameter filters based on the parametric regions shown in Figure 10. The result of this analysis are shown in Figure 13.

It is seen that in the case of the cross-ply composite (Figure 13(a)), the first damages was in the form of matrix cracks (A type signals). A few isolated matrix cracks occurred very early in the loading process. However, the substantial matrix damage did not begin up to the stress levels of about $50 \%$ of the ultimate strength. The increase in the matrix damage at the stress level was followed by some fiber breakage (B type signals) and, almost simultaneously, by the "macrodamage" development (C type signals). Comparison with the on-line observations showed at the "macrodamage" in this composite was in the form of delaminations, rather than the longitudinal splitting observed in the $[0]_{8}$ composite. Note that, in general, two types of delamination damage may occur in a multidirectional laminate, edge delamination and ply damaged-induced delamination. These delaminations may differ with regard to their location or size. However, both types of delaminations can be expected to produce substantial acoustic emission signals as they are associated with a considerable out-of-plane displacement. It was assumed here that type $C$ signals in the laminated composites were produced by both edge delaminations and ply damage-induced delaminations. The matrix damage accumulation showed a tendency to saturate in the cross-ply composite (A type signals in Figure 13(a)). A satura- 
(a)

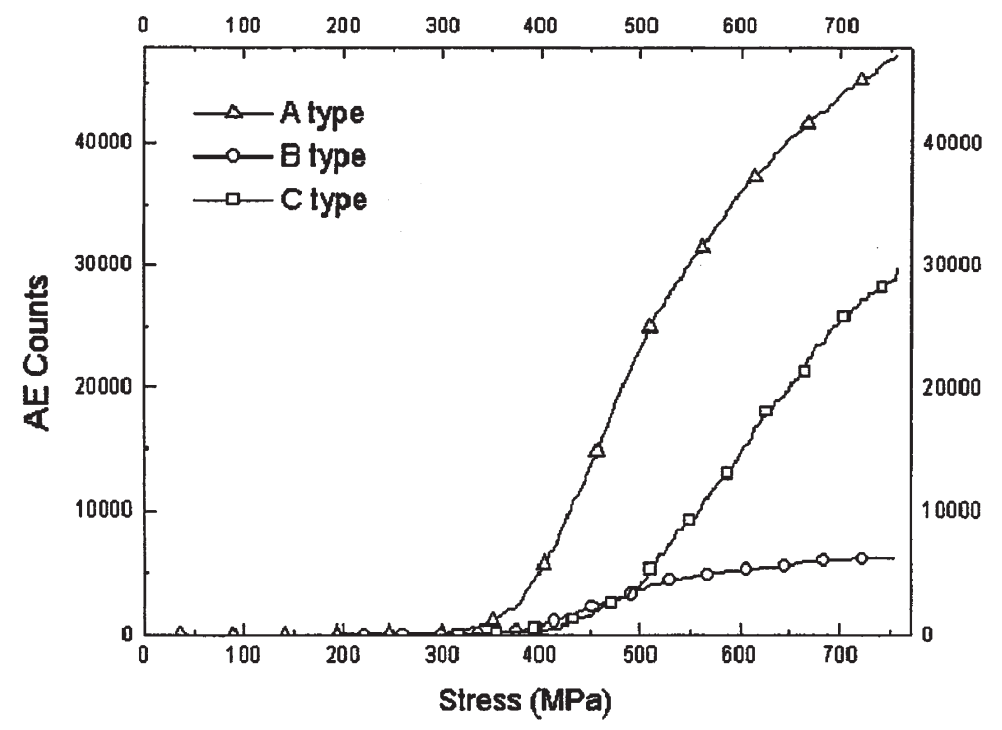

(b)

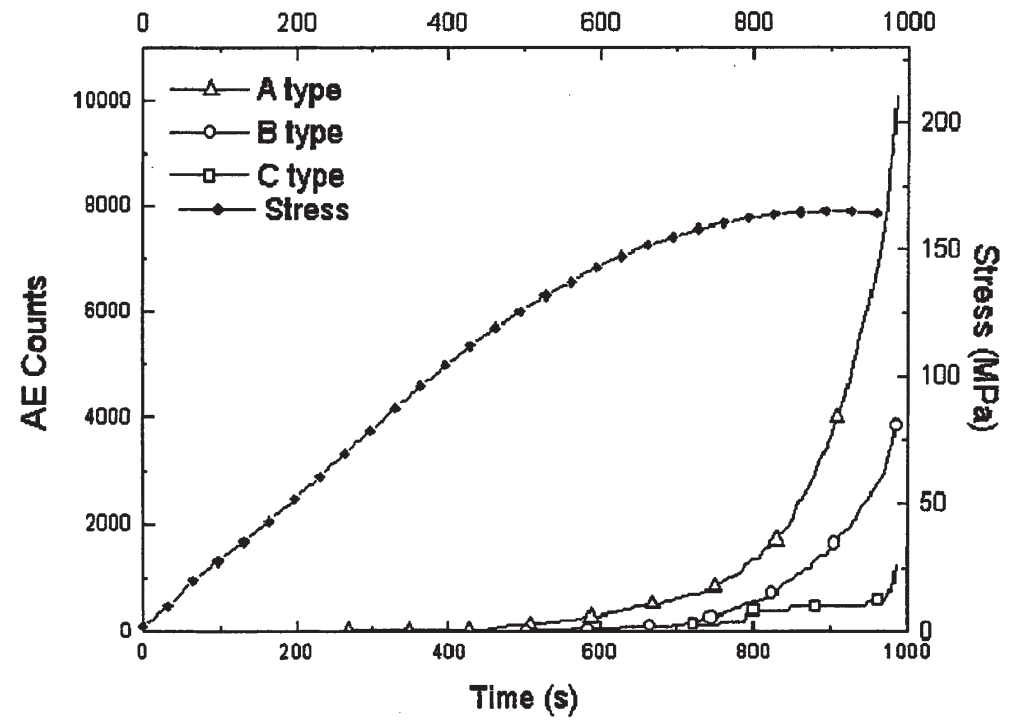

Figure 13. Classified AE histories for laminated composites: (a) $[0 / 90]_{3 \mathrm{~S}}$ and (b) $[ \pm 45]_{4 \mathrm{~S}}$.

tion of matrix cracks in the $90^{\circ}$ plies of a cross-ply composite is, in fact, expected, based on the results of published experimental and theoretical analyses. The fiber damage accumulation in the composite was not substantial (B type signals in Figure 13(a)). The fiber damage also showed tendency to saturate. The observed similarities between the fiber and matrix damage accumulation indicated that the fiber breaks in the cross-ply composite might be related to the matrix cracks. For example, isolated fiber breaks in the 0-plies could occur in the vicinity of the matrix cracks in the 90-plies. The delamination in this composite grew steadily to failure. The overall AE activity in the $[0 / 90]_{3 S}$ composite was dominated by the matrix damage and delaminations. The AE history analysis correlated, in general, with the on-line observations and the observed failure of the composite specimen (Figure 14(a)). 
(a)

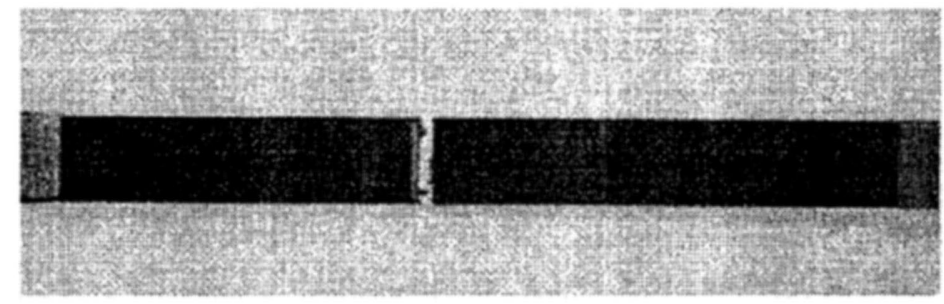

(b)

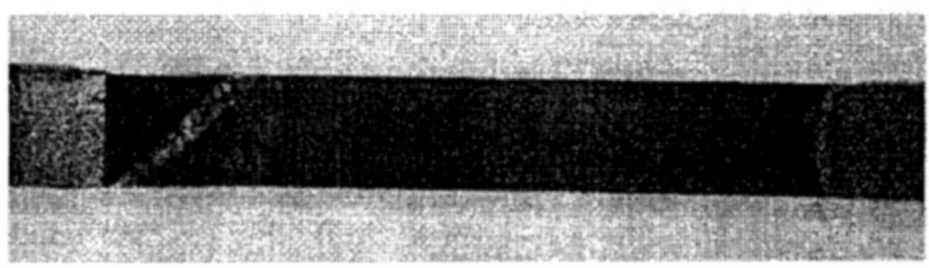

Figure 14. Failed specimens of laminated composites: (a) $[0 / 90]_{3 S}$ and (b) $[ \pm 45]_{4 S}$.

The classified time histories of the damage evolution in the angle-ply composite are shown in Figure 13(b), where the stress-time dependence is also included, for reference. The analysis showed that, when compared with the cross-ply lay-up shown in Figure 13(a), a substantial damage accumulation in this material started later in the loading process. The damage sequence was the same as described for the cross-ply composite: matrix cracks developed first, to be followed by fiber breaks and delaminations. However, no saturation was observed for any of the damage modes in this laminate. In contrast to the cross-ply composite, the rates of accumulation of all three types of damage accelerated monotonically until failure. This is consistent with the fact that no saturation of any damage mechanism is expected in an angle-ply laminate. The damage process in this composite was dominated by the matrix cracks and the fiber breaks. Little delamination damage was detected. The latter may seem unusual as the delamination damage is practically inevitable in an angle-ply composite, at least before failure. Analysis of the failed specimen (Figure 14(b)) showed, however, that the final failure with some delamination occurred outside the acoustic gauge zone. The AE signals from this delamination were, therefore filtered out by the location filtering procedure described above. Thus, the results of $\mathrm{AE}$ analysis of the angle-ply composite corroborate the expected and observed damage in this material.

\subsubsection{Evaluation of quality of parametric filtering}

The multiparameter filters used to obtain the classified AE histories for the laminated composites were developed based on the transient-parametric analysis of the unidirectional composites. The application of these filters to the analysis of the laminated composites was based on the observed similarity of the three characteristic waveforms in the unidirectional and the laminated composites. As noted in Section 3.5.1, the results of the classified AE analysis for the laminates seemed to correlate reasonably well with the observed and expected damage in these composites. A direct check of the applicability of the multiparameter filter definitions across the composite lay-ups is presented in this section by means of an inverse analysis.

The procedure was as follows. The AE signals from the particular parametric region were randomly selected and their parametric records were extracted from the parametric AE file. The waveforms for these signals were found in the transient AE file using the transient index. The frequency spectra were then computed for these waveforms using FFT. Finally, the waveforms and their spectra 
Table 2. Characteristic waveform content for laminated composites

\begin{tabular}{lllll}
\hline Laminate & $\begin{array}{l}\text { Parametric } \\
\text { region }\end{array}$ & $\begin{array}{l}\text { Total checked } \\
\text { waveforms }\end{array}$ & $\begin{array}{l}\text { Correct } \\
\text { waveforms }\end{array}$ & $\begin{array}{l}\text { Success } \\
\text { rate }(\%)\end{array}$ \\
\hline$[0 / 90]_{35}$ & A & 445 & 296 & 67 \\
& B & 216 & 134 & 62 \\
{$[ \pm 45]_{45}$} & A & 813 & 465 & 57 \\
& B & 390 & 321 & 82 \\
\hline
\end{tabular}

were evaluated for shape and classified accordingly. Both the cross-ply and angle-ply laminates were analyzed. Due to the large number of the AE signals in both laminates, a partial check based on the analysis of several hundred signals of each type was performed.

First, the transient records of the signals with long duration were evaluated. The analysis showed that the majority of these signals from both laminates were of the type $\mathrm{C}$. Then, the signals with parameters falling into the parametric regions for type A and B waves were analyzed and enumerated. The results of this evaluation are listed in Table 2 . The analysis of the cross-ply composite showed that over $60 \%$ of all signals in both parametric regions had the correct transient waveform. For the angle-ply composite, the success rate was $57 \%$ for the A type signals and $82 \%$ for the B type signals. The balance in all cases was composed primarily of the unclassified waveforms. There were few or no waveforms of the opposite type found in the parametric regions of each particular type. The success rates in Table 2 can be considered reasonable, taking into account the complexity of the damage and wave propagation processes in composites and the number of variables involved in the damage accumulation. Overall, the results of this analysis showed that the parametric filters developed for the unidirectional composites could be applied to separate the AE histories in the laminated composites with a reasonable reliability.

\section{Concluding remarks}

A new method of AE analysis of histories of damage micromechanisms was developed and demonstrated. The method was based on a contribution of transient and parametric AE analyses. The method was illustrated by the analysis of damage evolution in four graphite-epoxy composites. The characteristics $\mathrm{AE}$ waveforms were classified by the transient $\mathrm{AE}$ analysis. The parametric regions occupied by these waveforms in the amplitude-rise time parametric space were identified by the transient-parametric analysis of the unidirectional composites. The multiparameter filters based on these regions were used to extract the histories of different waveforms for both unidirectional and laminated composites. Physical damage observations were used to correlate the characteristics waveforms with the damage micromechanisms. The quality of the multiparameter filtering for the laminated composites was demonstrated by an inverse parametric-transient analysis.

The hybrid method provides a means to combine the power of the transient AE classification with the relative simplicity of the parametric filtering. The transient waveform classification of the acoustic signals is expected to be more robust when compared to the parametric classification. The AE parameters of signals from different damage mechanisms often overlap due to the complexity and variability of the damage and wave propagation processes in composites. In many cases, the parametric analysis cannot discriminate between the damage mechanisms. In the examples studied in this work, only one of the four composites, i.e. the cross-ply laminate, exhibited multiple peaks on the distribution histograms. Only one of the two observed peaks could be attributed to a particular damage mechanism. All other composites did not produce multiple peaks in the distribution histograms. None of the composites produced multiple clusters in the multiparameter correlation plots. As a result, even a 
powerful cluster analysis method could not be applied for parametric signal discrimination. The proposed hybrid transient-parametric analysis, however, enabled the separation of the AE signals from different damage mechanisms by the multiparameter filtering. Reasonable correlation was observed between the results of the acoustic analysis and physical observations.

It should be noted that the characteristic waveforms and the parametric regions occupied by these waveforms are expected to vary from one material to the other, and a separate analysis should be performed for each particular composite system. The generality of the characteristic waveforms and the parametric regions observed for the four different composite materials in this work indicate possible transferability of the parametric filters among different composite lay-ups within the same material family. Further studies are needed, however, to verify it.

Since the multiparameter filtering procedure requires only the parametric AE data, it is expected that the developed method will be especially advantageous for the study of fatigue damage histories in composites, where the full transient waveform analysis may be prohibitive or impractical.

\section{Acknowledgments}

This work was supported by the Air Force Office for Scientific Research under grant no. F49620-96-10458. The program directors were Dr. W. Jones and Dr. O. Ochoa. The materials for this study were provided by the Hexcel Corporation.

\section{References}

Allen, D. H., Harris, C. E., and Groves, S. E., 1987. International Journal of Solids and Structures 23, p. 1301.

Allen, D. H., Harris, C. E., and Groves, S. E., 1987. International Journal of Solids and Structures 23, p. 1319.

Awerbuch, J., and Ghaffari, S., 1988. Journal of Reinforced Plastics and Composites 7, p. 245.

Bakuckas, J. G., Jr., Prosser, W. H., and Johnson, W. S., 1994. Journal of Composite Materials 28 4, pp. 305-328.

Batdorf, S. B., 1982. Journal of Reinforced Plastics and Composites 1, p. 153.

Chang, C., and Sun, C. T., 1988. Composite Science and Technology, 213-236.

Curtin, W. A., 1993. Journal of Mechanics and Physics of Solids 41, p. 217.

Curtin, W. A., 1993. Composites 23, p. 98.

Dzenis, Y. A., Joshi, S. P., and Bogdanovich, A. E., 1994. AIAA Journal 32, p. 357.

Dzenis, Y. A., Joshi, S. P., and Bogdanovich, A. E., 1993. AIAA Journal 31, p. 2329.

Dzenis, Y. A., and Joshi, S. P., 1997. AIAA Journal 35, p. 1057.

Dzenis, Y., and Qian, J., 1998. In: Gowayed, Y., Abd El Hady, F. (Eds.), International Conference on Advanced Composites ICAC '98, Hurghada, Egypt, p. 498 (extended version submitted for publication to Journal of Acoustic Emission).

Ely, T. M., and Hill, E. v. K., 1995. Materials Evaluations, Feb: 288-294.

Gorman, M. R., 1992. Composite materials, 4th International Symposium on AE from Composites, Seattle, 395-400.

de Groot, P. J., Wijnen, P. A. M., and Janssen, R. B. F., 1995. Composite Science and Technology 55, pp. 405-412.

Gunyaev, G. M., 1985. In: Handbook of Composites, vol. 3. Failure Mechanics of Composites, Elsevier, New York, p. 376.

Harlow, D. G., and Phoenix, S. L., 1979. International Journal of Fracture 15, p. 321.

Kloua, H., Maslouhi, A., and Roy, C., 1995. Canadian Aeronautics and Space Journal 41, p. 21.

Kouvarakos, M., and Hill, E. v. K., 1996. Materials Evaluations, Sept: 1025-1031. 
Ladeveze, P., Allix, O., Cluzel, C., and d'Evry, I. U. T., 1993. In: Voyiadjis, G. Z. (Ed.), Damage in Composite Materials, Elsevier, New York, p. 195.

Luo, J.-J., Wooh, S.-C., and Daniel, I. M., 1995. Journal of Composite Materials 29 15, pp. 1946-1961.

Masters, J. E. (Ed.), 1992. Damage Detection in Composite Materials, ASTM STP 1128, American Society for Testing and Materials, Philadelphia.

Masters, J. E., and Reifsnider, K. L., 1980. Damage in Composite Materials, ASTM STP 775, pp. 40-65.

Ono, K., and Huang, Q., 1996. Personal communication.

Ovchinskii, A. S., 1988. Fracture Process in Composite Materials: Computer Simulation of Micro- and Macromechanisms, Nauka, Moscow (in Russian).

Phoenix, S. L., 1993. Composite Science and Technology 48, p. 65.

Pipes, R. B. (Ed.), 1979. Nondestructive Evaluation and Flaw Criticality for Composite Materials ASTM STP 696, American Society for Testing and Materials, Philadelphia.

Prosser, W. H., Jackson, K. E., Kellas, S., Smith, B. T., McKeon, J., and Friedman, A., 1995. Materials Evaluations, Sept: 1052-1058.

Reifsnider, K. L., Lesco, J., and Case, S., 1995. COMPOSITES '95: Recent Advances in Japan and the United States, Kyoto, Japan, p. 49.

Rosen, B. W., 1964. AIAA Journal 2, p. 1985.

Shiwa, M., Carpenter, S., and Kishi, T., 1996. Journal of Composite Materials 18, p. 2019.

Summerscales, J. (Ed.), 1987. Non-Destructive Testing of Fiber-Reinforced Plastic Composites, vol. 1. Elsevier, Amsterdam.

Tamuzh, V. P., 1979. In: Sih, G. C., Tamuzh, V. P. (Eds.), Fracture of Composite Materials, Sijthoff, Alphen aan den Rijn, The Netherlands, p. 13.

Tsai, S. W., and Hahn, H. T., 1980. Introduction to Composite Materials. Technomic, Westport, Conn.

Wevers, M., Verpoest, I., De Meester, P., and Aernoudt, E., 1991. In: Sachse, W., Roget, J., Yamaguchi, K. (Eds.), Acoustic Emission: Current Practice and Future Directions, ASTM STP 1077 American Society for Testing and Materials, Philadelphia, p. 416.

Williams, R. S., and Reifsnider, K. L., 1974. Journal of Composite Materials 8, p. 340.

Yamaguchi, K., Oyaizu, H., Johkaji, J., and Kobayashi, Y., 1991. In: Sachse, W., Roget, J., Yamaguchi, K. (Eds.), Acoustic Emission: Current Practice and Future Directions, ASTM STP 1077 American Society for Testing and Materials, Philadelphia, p. 123.

Zweben, C., 1968. AIAA Journal 6, p. 2325. 